\title{
Role of hyper-reflective spots in predicting outcomes of intravitreal therapy in diabetic macular edema: A systematic review and meta-analysis
}

\section{Pratyusha Ganne $^{1^{*}}$, MS; Nagesha C Krishnappa ${ }^{2^{*}}$, M.S; Ganne Chaitanya ${ }^{3}$, MBBS, PhD; Siddharth K Karthikeyan ${ }^{4}$, M.Sc}

${ }^{1}$ Department of Ophthalmology, All India Institute of Medical Sciences, Mangalagiri, Guntur, India

${ }^{2}$ Department of Vitreo-Retina, BW Lions Superspeciality Eye Hospital, Bangalore, India

${ }^{3}$ Epilepsy and Cognitive Neurophysiology Lab, Department of Neurology, University of Alabama at Birmingham, USA

${ }^{4}$ Department of Optometry, Manipal College of Health Professionals, Manipal Academy of Higher Education. Manipal, Karnataka, India

\section{Running title: A review on HRS in DME}

\section{Corresponding author}

Nagesha C Krishnappa

Department of Vitreo-Retina

B W Lions Superspeciality Eye Hospital

Bangalore, India

drnageshck2006@yahoo.com

$+919566262008$

No funding has been received for this work.

None of the authors has any conflicting interests or proprietary interests to disclose.

Number of words in the abstract: 346

Number of words: 2969

Number of references: 46

Number of figures: 2

Number of tables: 4

Numbers of Appendix material: 1 
medRxiv preprint doi: https://doi.org/10.1101/2021.04.16.21255622; this version posted April 18, 2021. The copyright holder for this preprint (which was not certified by peer review) is the author/funder, who has granted medRxiv a license to display the preprint in perpetuity.

All rights reserved. No reuse allowed without permission.

Keywords: Biomarker; Diabetic macular edema; Hyperreflective spots, Macular thickness; Optical coherence tomography, Prognosis; Visual acuity 


\section{Abstract}

Purpose: Predicting response to intravitreal therapy in DME has become a challenging task. Individual studies have shown that HRS could be a reliable biomarker. This systematic review aimed to determine if there was a quantitative reduction in hyperreflective spots (HRS) following intravitreal therapy in diabetic macular edema (DME), if the type of intravitreal therapy (anti-VEGF versus steroid) had differential effects on quantitative HRS change and finally, if HRS at the start of therapy was associated with improvement in visual acuity (VA) or reduction in central macular thickness (CMT). We also aimed at bringing out the lacunae in the existing literature on HRS in DME and propose goals for future studies.

Methods: PubMed/MEDLINE, Scopus, ProQuest, CINAHL, Wiley online and Web of Science were searched based on MOOSE guidelines for non-randomized studies evaluating HRS as a biomarker in DME (between $1^{\text {st }}$ January 2011 and $1^{\text {st }}$ July 2020). Publication bias was analyzed using Begg and Mazumdar rank correlation test and funnel plots. Heterogeneity was assessed using the $\mathrm{I}^{2}$ statistic. Meta-analysis was done using a random-effects model.

Results: A total of 1168 eyes from 19 studies were eligible for inclusion. Pooled standardized mean differences showed that intravitreal therapy was associated with a reduction in quantitative $\mathrm{HRS}\left(\mathrm{z}=-6.3, \mathrm{CI}_{95 \%=}-1.09\right.$ to $\left.-0.55, \mathrm{p}<0.0001\right)$. Extreme between-study heterogeneity was observed $\left(\mathrm{I}^{2}=93.2 \%\right)$ with significant publication bias. There was no difference in outcomes between anti-VEGF and steroid therapies $(\mathrm{p}=0.23)$. No definite conclusions could be drawn regarding the predictive value of HRS in determining the final VA and CMT.

Conclusion: This review could conclude that there is a definite reduction in quantitative HRS following either form of intravitreal therapy. Our conclusion about 
medRxiv preprint doi: https://doi.org/10.1101/2021.04.16.21255622; this version posted April 18, 2021. The copyright holder for this preprint (which was not certified by peer review) is the author/funder, who has granted medRxiv a license to display the preprint in perpetuity. All rights reserved. No reuse allowed without permission.

the role of HRS in predicting visual outcome and CMT change was limited by the number of analyzable studies owing to the wide variation in the study designs, methods and reporting. 


\section{Introduction}

Intravitreal anti-vascular endothelial growth factor (anti-VEGF) therapy has emerged as the first-line treatment for diabetic macular edema (DME) in the last decade after the landmark RISE/RIDE trials and Diabetic Retinopathy Clinical Research Network (DRCR.net) studies demonstrated a significant visual acuity (VA) improvement in as many as $60 \%$ of the eyes treated with these injections. ${ }^{1,2}$ However, as much as $50 \%$ of the eyes in protocols I and $\mathrm{T}$ of DRCR.net did not respond adequately to these injections. ${ }^{3,4}$ Intravitreal steroids in the form of dexamethasone implants are being used in such patients not responding to anti-VEGF injections. ${ }^{5,6}$ The rationale behind using steroids stems from the assumption that inflammation plays a significant role in some eyes with DME. ${ }^{7,8}$ However, a small subset of patients can show suboptimal response to dexamethasone implants as well. ${ }^{9}$ In a real-life scenario, predicting which patient will or will not respond to intravitreal treatment has become a challenging task. Hence, a lot of research is being done to understand what factors at baseline predict functional and morphological responses to these injections and which sub-groups of patients benefit from intravitreal steroids/ anti-VGEF injections.

A number of biomarkers are being evaluated on optical coherence tomography (OCT) scans to predict responses like neurosensory detachment (NSD), ${ }^{10,11}$ hyperreflective spots (HRS), ${ }^{12}$ ellipsoid zone (EZ) line integrity, cystoid macular edema $(\mathrm{CME})^{10}$ and disorganization of retinal inner layers (DRIL). ${ }^{13}$ HRS are small, dot-like lesions that are of equal or higher reflectivity than the retinal pigment epithelium (RPE) / nerve fiber layer with absent back shadowing on OCT. ${ }^{14-17}$ Several theories have been postulated to explain the pathogenesis of these spots but their exact nature is still unclear. These spots are thought to be extravasated lipoproteins (precursors of hard exudates), ${ }^{18}$ inflammatory cells (leucocytes, activated microglia), ${ }^{19,20}$ migrated RPE 
cells ${ }^{21}$ or photoreceptor fragments. ${ }^{22}$ Significant research is underway to understand the predictive value of this biomarker in determining the final VA, reduction in central macular thickness (CMT), recurrence patterns and duration of action of intravitreal implants. ${ }^{14,15,22-26}$

The majority of the current literature on HRS in DME consists of small retrospective/prospective cohort studies. Though some studies have shown conflicting results, it seems promising that HRS could be used as a reliable marker of disease burden and response to therapy in DME. Hence, we tried to synthesize the available information on HRS to (1) investigate if there was a reduction in quantitative HRS following intravitreal therapy (2) determine if the type of intravitreal therapy (antiVEGF vs. steroid) had differential effects on quantitative HRS change, and finally (3) if change in post-treatment quantitative HRS/ baseline HRS counts were associated with improvement in VA or reduction in CMT. Finally, we would like to draw attention to the lacunae in the existing literature on HRS in DME and suggest goals for future studies so that the true potential of this biomarker can be understood.

\section{Methods}

We conducted this systematic review in accordance with Meta-Analyses and Systematic Reviews of Observational Studies (MOOSE) guidelines. ${ }^{27}$ Institutional review board exemption was obtained. The protocol has been registered in the International Prospective Register of Systematic Reviews (PROSPERO) (CRD42020186820).

\section{Selection criteria}

This review included all articles that described HRS as an outcome predictor after intravitreal therapy in DME from peer reviewed journals published in the electronic

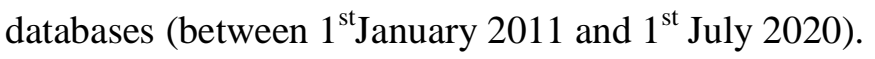


We excluded studies: (1) not available in English, (2) published in books or grey literature, conference abstracts, review, comments, letter to editor, case series $(<5$ subjects) (3) with insufficient quality (4) where the results of DME were combined with other causes of macular edema like vein occlusion (5) where additional interventions were done during the study period like laser, vitrectomy, etc. (6) performed in non-human subjects (7) where time domain OCT machines were used.

\section{Search Strategy}

The following databases were searched: PubMed/MEDLINE, Scopus, ProQuest, CINAHL, Wiley online and Web of Science. PICO (participants, intervention, and comparison and outcomes) format search strategy was used to search the databases mentioned.

Key words used included: DMO, DME, diabetic retinopathy, DR, macular edema, macular odema, bevacizumab, anti-VEGF, ranibizumab, antivascular endothelial growth factor, BVZ, dexamethasone implant, steroid, intravitreal, intra-vitreal, injection, avastin, lucentis, accentrix, aflibercept, eyelea, ozurdex, triamcinolone acetonide, IVTA, steroid, conbercept, optical coherence tomography, SD-OCT, OCT, hyperreflective, hyper-reflective, hyper reflective, spots, foci, dots, material, points, aggregates, particles, clumps, elements, HRF, HS, HRS, HF, HRD, inflammatory biomarkers, prognostic markers, central macular thickness, CMT, CST, macular volume, foveal thickness, FT, best corrected visual acuity, VA, BCVA, outcomes. The full search strategy for MEDLINE using keywords is detailed in Appendix 1. 
All titles and abstracts were pooled to a reference management database and duplicates removed. All titles and abstracts were independently screened by two board certified vitreo-retinal surgeons ( $\mathrm{PG}$ and $\mathrm{NCK}$ ) and full text copies of all potentially relevant papers were retrieved. Any conflict was resolved by mutual discussion. The reference list of each selected article was reviewed to ensure no relevant article was overlooked.

\section{Data extraction}

Data from the final full-text articles was extracted by PG and was verified by NCK. Any conflicts were resolved by mutual discussion. The following data was extracted: (1) title, main author and publication year, (2) study design and sample size, (3) participant data, (4) intravitreal drug, (5) age, (6) gender distribution, (7) OCT machine used, (8) VA, (9) confounding factors (10) follow-up (11) area of the OCT scan over which HRS were analyzed, (12) HRS count before and after treatment, (13) association (i.e, correlation/ regression) between HRS, VA and CMT.

\section{Assessment of methodological quality and risk of bias}

The quality and risk of bias of the articles included in full-text review was assessed by PG and SK using the National Institute of health (NIH) Study Quality Assessment

Tool. ${ }^{28}$ Questions with answer 'yes' were scored as 1 and answer 'no' / 'cannot determined' / 'not reported' as 0 . Any conflict was resolved by mutual discussion. Total score for each study $=$ (the total number of questions with 'yes' as an answer / the total number of questions) $x 100$ (Note: If the answer to a question was "not applicable', the question was excluded from both the numerator and the denominator). 
Studies were graded as high quality (80-100\%), moderate quality (60-80\%) and low quality $(<60 \%)$.

\section{Statistical Analysis}

Meta-analysis

For the purposes of completion of this systematic review, we performed a randomeffects meta-analysis, whilst being aware of the need to explore possible heterogeneity of result-reporting in the various studies, as the topic is not thoroughly investigated as yet and also considering that fact that these studies may not all be randomized controlled trials or studies that bag Level-II evidence or higher. All the outcomes of interest (i.e. quantitative HRS reduction, difference in quantitative HRS reduction between steroid and anti-VEGF therapy, and post-treatment change in VA) were continuous variables. After integrating and synthesizing effect sizes from different studies, the variance of combined true effect sizes among the studies were estimated using Hedge's g for all outcomes (with 95\% CI). Random-effects model was used to account for heterogeneity between studies. Proportion of the variability that was due to heterogeneity was estimated using $\mathrm{I}^{2}$ statistics. Prediction interval (PI) of the combined effect size was estimated. Sub-group analysis was performed using ANOVA of sum of squares. ${ }^{29}$

Pre/post-treatment HRS counts (mean $\pm \mathrm{SD}$ ) were parsed for meta-analysis to the test effect of intravitreal injections, following which a subgroup analysis was performed to differentiate outcomes of anti-VEGF and steroid sub-groups. Mean and SD of change scores of VA pre and post-treatment were parsed. We used imputation method to estimate SD of change scores when not explicitly reported by authors. 
Publication bias was analyzed using Begg and Mazumdar rank correlation test $(\Delta \mathrm{x}-\mathrm{y}$, Kendall Tau a, PI limits and CI limits) and funnel plots.

\section{Results}

\section{Included studies}

Figure 1 shows the flow diagram to summarize inclusion of relevant studies.

\section{Quality of the studies}

Nineteen studies were identified (thirteen were retrospective cohort studies, ${ }^{12,15-}$ 17,24,26,30-36 three were prospective cohort studies, ${ }^{37,38,41}$ two were case series ${ }^{14,39}$ and one was a case-control study ${ }^{40}$ ). The quality score of the studies is shown in Table 1.

\section{Baseline characteristics (Table 1)}

A total of 1168 eyes of 942 patients (mean age: $64.3 \pm 4.9$ years, males: $59.4 \%$ ) were analyzed for HRS from the above 19 studies. Eight studies evaluated the response to anti-VEGF injections [intravitreal ranibizumab (IVR), intravitreal bevacizumab (IVB), and Conbercept], ${ }^{16,24,30-32,35,36,40} 11$ studies to dexamethasone implant ${ }^{12,14,26,32-34,36-39,41}$ and 2 studies to the sequential use of anti-VEGF and dexamethasone. ${ }^{15,17}$ The model of spectral domain OCT used, varied among the studies: 14 used SpectralisOCT ${ }^{\mathrm{TM}}$ (Heidelberg Engineering, Heidelberg, Germany), ${ }^{12,14-17,24,26,30-32,34,35,38,39} 3$ used Cirrus HD-OCT ${ }^{\mathrm{TM}}$ (Carl Zeiss Meditec, Dublin, CA, USA), ${ }^{33,37,41} 1$ each Retina scan ${ }^{\mathrm{TM}}$ (RS3000 advance; Nidek) ${ }^{40}$ and DRI-SSOCT Triton plus ${ }^{\mathrm{TM}}$ (Topcon Medical Systems Europe, Milano, Italy). ${ }^{36}$ The measurement of HRS was done over different area sizes in the macula (12 studies used $3000 \mu \mathrm{m}$ area, ${ }^{12,14-17,26,32-34,36,38,41} 4$ studies used $1000 \mu \mathrm{m}$ area, ${ }^{24,30,35,39} 2$ studies used $1500 \mu \mathrm{m}$ area ${ }^{31,37}$ and 1 study used area between $500-1500 \mu \mathrm{m}$ from the center of the fovea). ${ }^{40}$ 
Change in quantitative HRS with intravitreal therapy (Table 2)

Studies where HRS counts (mean \pm SD) were available before and after treatment were included in this analysis. There were a total of 12 studies. Quantitative HRS change with anti-VEGF and dexamethasone injections was reported in seven studies each.

All 7 studies where intravitreal anti-VEGF injections were used ${ }^{16,17,30-32,35,40}$ and 6 out of the 7 studies where dexamethasone was used ${ }^{17,26,32,34,37,39}$ reported a decrease in quantitative HRS. In the subgroup of patients whose macular edema did not respond to dexamethasone or IVB, there was no significant HRS reduction. ${ }^{17}$

Layer-wise analysis of HRS was done in 6 studies. However, the definition of inner and outer retinal layers was variable across the studies. Inner retina (IR) was defined as extending from internal limiting membrane (ILM) to outer nuclear layer (ONL) in 3 studies, ${ }^{17,31,35}$ ILM to inner nuclear layer (INL) in 1 study $^{26}$ and as INL in 1 study. ${ }^{16}$ Similarly, outer retina (OR) was defined as extending from external limiting membrane (ELM) to RPE in 2 studies, ${ }^{17,31}$ ELM to photoreceptors in 1 study ${ }^{35}$ and ELM to outer plexiform layer (OPL) in 2 studies. ${ }^{16,26}$ One study analyzed HRS in three layers i.e., ILM to inner plexiform layer (IPL), INL to OPL and ONL. ${ }^{40}$

\section{HRS change in steroid versus anti-VEGF treated eyes (Table 2 and Figure 2A)}

Two studies compared the change in HRS counts between these two classes of drugs, in treatment naive eyes. ${ }^{32,36}$ Vujosevic et $\mathrm{al}^{32}$ showed a greater reduction in HRS in dexamethasone treated eyes $(n=15)$ versus IVR treated eyes $(n=18)(24.7 \%$ versus $8.0 \%, p=0.03$ ) when all baseline parameters were matched. In another study by the same author, the decrease in HRS was not found to be different between the two treatment groups $(\mathrm{p}=0.135) .{ }^{36}$ However, note that in this study, the baseline HRS 
counts were significantly higher in the dexamethasone group compared to the IVR group $(\mathrm{p}=0.003)$. Hwang et $\mathrm{al}^{17}$ noted that baseline HRS numbers were higher in eyes that did not respond to IVB. When such eyes were treated with dexamethasone implant, a significant reduction in HRS was noted.

\section{Baseline HRS and Change in VA (Table 3 and Figure 2B)}

A total of 14 studies were analyzed. Five studies made a qualitative reporting of HRS as present or absent at baseline $e^{12,14,24,38,41}$ while in the rest a quantitative assessment of HRS was done. Of these, 3 studies had categorized the patients into those with HRS $<10-15$ and those with HRS $>10-15$ on baseline scans. ${ }^{15,33,39}$ In the rest 6 studies, baseline HRS counts were correlated with final VA using regression/correlation statistics. ${ }^{16,30,31,35,37,40}$

Three studies showed that higher HRS counts at baseline were associated with worse final VA. ${ }^{31,35,38}$ Five studies showed no correlation between baseline HRS counts and final VA. ${ }^{15,16,33,39,40}$ In a study by Cavalleri et al, ${ }^{15}$ dexamethasone therapy resulted in a greater gain in VA in eyes with high baseline HRS counts compared to IVB. Bonfiglio et $\mathrm{al}^{14}$ and Yoshitake et $\mathrm{al}^{24}$ compared eyes with and without HRS at baseline and showed a greater gain in VA following dexamethasone and anti-VEGF injections respectively in eyes with HRS. Zur et $\mathrm{al}^{12}$ reported a greater gain in eyes without HRS at baseline ${ }^{12}$ and Menezo et $\mathrm{al}^{41}$ showed no association between gain in VA and the presence of HRS at baseline.

\section{Baseline HRS and CMT change (Table 3)}

A total of 10 studies were included for this analysis. In 3 studies, the patients were grouped as those with or without HRS at baseline. ${ }^{14,24,41}$ Bonfiglio et al ${ }^{14}$ and 
Yoshitake et $\mathrm{al}^{24}$ reported greater reduction in CMT in eyes with HRS compared to those without. Menezo et $\mathrm{al}^{41}$ found no association between the two parameters. Two studies which evaluated the association between a decrease in HRS and change in CMT showed contrasting results, with Liu et $\mathrm{al}^{35}$ reporting a significant correlation between the reduction in inner and total retinal HRS and the decrease in CMT at 3 months $\left(\mathrm{r}=0.422, \mathrm{p}=0.032\right.$ and $\mathrm{r}=0.429, \mathrm{p}=0.029$ respectively) and Framme et $\mathrm{al}^{30}$ reporting no significant association between the two variables at the end of 1 month. Vujosevic et $\mathrm{al}^{32}$ showed greater CMT reduction in eyes with more HRS (>87) at baseline than those with less HRS $(<87)(\rho=-0.28$, p=not reported $)$. Schreur et al ${ }^{16}$ reported that the number of HRS at baseline was independently associated with a decrease in CMT $\left(\beta_{\text {standardized }}=-2.61, \mathrm{p}=0.006\right)$. On the contrary, Fonollosa et $\mathrm{al}^{33}$ found that the CMT reduction was not significantly different between groups with scare $(<10)$ or abundant $(>21)$ HRS. Finally, Kang et $\mathrm{al}^{31}$ and Vujosevic et $\mathrm{al}^{40}$ found no significant correlation between the baseline HRS counts and the final retinal thickness.

Meta-analysis

Meta-analysis on 12 studies to analyze the quantitative HRS change following intravitreal therapy (figure 2A), showed high heterogeneity in the studies $\left(\mathrm{I}^{2}=\right.$ 93.16\%). Funnel plot showed an asymmetry in distribution and significant publication bias $\left(\Delta=-100\right.$; Kendell's Tau a $=-0.526, \mathrm{CI}_{95 \%}=-0.47$ to -0.36 , PI $=-1.57$ to 0.73 , $\mathrm{p}=0.001)$. There was no significant difference between dexamethasone (Hedges' $\mathrm{g}=-$ $1.0, \mathrm{CI}_{95 \%}=-1.42$ to -0.57$)$ and anti-VEGF groups (Hedges' $\mathrm{g}=-0.69, \mathrm{CI}_{95 \%}=-0.99$ to $-0.38)$ in terms of HRS reduction $\left(\mathrm{Q}^{*}=1.4, \mathrm{df}=1, \mathrm{p}=0.23\right)$. 
Due to the heterogeneity in defining the layers, layer-wise changes were not analyzed in meta-analysis. To analyze the association between HRS and VA, we performed a meta-analysis on three studies (figure 2B). ${ }^{12,14,41}$ Presence/absence of HRS at the start of the therapy was not associated with improved VA at the end of treatment (Hedges' $\mathrm{g}=0.237, \mathrm{CI}_{95 \%}=-1.39$ to $\left.1.87, \mathrm{I}^{2}=84 \%, \mathrm{p}=0.5\right)($ Figure $2 \mathrm{~B})$.

We could not perform a meta-analysis to see the effect of HRS on CMT reduction due to wide heterogeneity in the way the data was reported.

\section{Discussion}

In this review, we found that there is a definite reduction in HRS counts following intravitreal therapy with no significant difference between anti-VEGF and steroid groups. The role of HRS in predicting visual outcome and CMT change was limited by the number of analyzable studies owing to the wide variation in the study designs, methods and reporting.

OCT as an investigating modality has revolutionized the treatment of DME. So far, the response to therapy was being predicted based on the type of edema with centreinvolving CME having the worst prognosis owing to the permanent structural damage to the neural elements in the fovea. However, recent research has identified additional biomarkers like NSD, HRS, EZ loss, ELM loss and DRIL to estimate the severity of the edema, decide the type of intravitreal drug to be used or predict functional and anatomical responses to intravitreal therapy. ${ }^{10-14}$

Various theories have been proposed regarding the exact nature of HRS. ${ }^{18-22}$ Of these, the hard exudate and inflammatory theories are most popular in DME. Cusick et al 
using immunochemistry found apolipoprotein-B deposits corresponding to the HRS in OCT sections. ${ }^{43}$ Intravitreal dexamethasone is a potent anti-inflammatory agent. AntiVEGF injections, although not as potent as steroids in their anti-inflammatory action, have been shown to have anti-activated microglial activity in addition to antiangiogenic property. ${ }^{44}$ The reduction or disappearance of HRS within 3 months of starting intravitreal therapy as seen in most studies of this review is a strong pointer towards their inflammatory origin. It may be hard to explain such rapid regression of well-formed hard exudates but at this stage the behavioral dynamics of the precursors of hard exudates (HRS) are still unknown.

The results of the meta-analysis did not show a significant effect of baseline HRS on the change in visual acuity. However, eyes with treatment naive $\mathrm{DME}^{15,16,30-32,35,37,40}$ as against those with refractory $\mathrm{DME}^{14,38,39}$ showed a positive correlation between HRS with VA gain (5/8 studies versus $0 / 3$ studies) and CMT reduction (7/8 studies versus 1/3 studies). Also, eyes where HRS was associated with NSD at baseline responded better and showed a positive correlation between HRS and VA improvement and CMT reduction with in first 2-3 months. ${ }^{14,31,36,40}$ Based on the above observations, we can hypothesize that inflammation plays a dominant role in treatment naive eyes or eyes with NSD when they present with HRS as evidenced by their prompt response to intravitreal injections.

The limitations of the studies included in this review are: retrospective design of most of these studies; small sample sizes in most; lack of uniformity in HRS evaluation as an outcome (variable macular areas over which HRS was analyzed, manual versus automated counting, variability in the definition of IR, OR and TR and masking of 
investigators); short duration of follow up; lack of adjustment for confounders like [blood lipid and sugar levels, ${ }^{45,46}$ type of macular edema (CME, DRT, SRD)], lack of uniformity in reporting the statistics and outcomes and significant publication bias. Also, there has been a lack of uniform definition of HRS in these studies. Framme et $\mathrm{al}^{21}$ described them as "hyperreflective foci of round or oval shape and of different sizes." Vujosevic et $\mathrm{al}^{40}$ described HRS as "small, punctiform discrete white lesions" with no reference to the exact size or reflectivity. Fonollosa et $\mathrm{al}^{33}$ cited de Benedetto et $\mathrm{al}^{18}$, who stated "small, round- or oval-shaped, well-circumscribed particles (no bigger than $40 \mu \mathrm{m}$ in diameter), with higher reflectivity than the background." Yoshitake et $\mathrm{al}^{24}$ considered "round or oval particles seen on the OCT images and corresponded to hard exudates in the fundus photographs" as HRS. Cavalleri et $\mathrm{al}^{15}$ considered the following morphologic characteristics to define HRS: reflectivity similar to that of nerve fiber layer; absence of back-shadowing; $<30 \mu \mathrm{m}$ diameter. No definition of the HRS were provided by Zur et $\mathrm{al}^{12}$, Chatziralli et $\mathrm{al}^{38}$, or Kang et $\mathrm{al}^{31}$. There is a need to standardize a number of factors before we understand these lesions. Hence, we recommend a stage-wise approach to understand the exact nature and role of this biomarker in DME. (Table 4)

In conclusion, HRS as a biomarker has been shown to be very promising in predicting therapeutic response to intravitreal treatment in DME in the individual studies. This review could conclude that there is a definite reduction in quantitative HRS following either form of intravitreal therapy. But, owing to the high heterogeneity in reporting, this meta-analysis could not summarize the predictive value of HRS in determining the VA and CMT outcomes. 
medRxiv preprint doi: https://doi.org/10.1101/2021.04.16.21255622; this version posted April 18, 2021. The copyright holder for this preprint (which was not certified by peer review) is the author/funder, who has granted medRxiv a license to display the preprint in perpetuity. All rights reserved. No reuse allowed without permission.

\section{Acknowledgements}

We thank Dr. Stela Vujosevic, MD, PhD, University Hospital Maggiore della Carità,

Corso Mazzini 18, 28100 Novara, Italy and Dinah Zur, MD, Tel Aviv University, Tel

Aviv, Israel for sharing the original data in order to conduct this meta-analysis. 


\section{References}

1. Sun JK, Jampol LM. The Diabetic Retinopathy Clinical Research Network (DRCR.net) and Its Contributions to the Treatment of Diabetic Retinopathy. Ophthalmic Res. 2019;62:225-230.

2. Nguyen QD, Brown DM, Marcus DM, et al. Ranibizumab for Diabetic Macular Edema: Results from 2 Phase III Randomized Trials: RISE and RIDE. Ophthalmology. 2012;119:789-801.

3. Gonzalez VH, Campbell J, Holekamp NM, et al. Early and Long-Term Responses to Anti-Vascular Endothelial Growth Factor Therapy in Diabetic Macular Edema: Analysis of Protocol I Data. Am J Ophthalmol. 2016;172:72-79.

4. Bressler NM, Beaulieu WT, Glassman AR, et al. Persistent macular thickening following intravitreous aflibercept, bevacizumab, or ranibizumab for centralinvolved diabetic macular edema with vision impairment: a secondary analysis of a randomized clinical trial. JAMA Ophthalmol 2018;136:257-269

5. Busch C, Fraser-Bell S, Iglicki M, et al. Real-world outcomes of non-responding diabetic macular edema treated with continued anti-VEGF therapy versus early switch to dexamethasone implant: 2-year results. Acta Diabetol. 2019;56:13411350.

6. Regillo CD, Callanan DG, Do DV, et al. Use of Corticosteroids in the Treatment of Patients With Diabetic Macular Edema Who Have a Suboptimal Response to Anti-VEGF: Recommendations of an Expert Panel. Ophthalmic Surg Lasers Imaging Retina. 2017;48:291-301.

7. Funatsu H, Noma H, Mimura $\mathrm{T}$, et al. Association of Vitreous Inflammatory Factors with Diabetic Macular Edema. Ophthalmology. 2009;116:73-9. 
8. Sonoda S, Sakamoto T, Yamashita T, et al. Retinal morphologic changes and concentrations of cytokines in eyes with diabetic macular edema. Retina. 2014;34:741-748.

9. Choi MY, Jee D, Kwon JW. Characteristics of diabetic macular edema patients refractory to anti-VEGF treatments and a dexamethasone implant. PLoS ONE. 2019;14:e222364.

10. Gerendas BS, Prager S, Deak G, et al. Predictive imaging biomarkers relevant for functional and anatomical outcomes during ranibizumab therapy of diabetic macular oedema. Br J Ophthalmol. 2018;102:195-203.

11. Sheu S-J, Lee Y-Y, Horng Y-H, et al. Characteristics of diabetic macular edema on optical coherence tomography may change over time or after treatment. Clin Ophthalmol Auckl NZ. 2018;12:1887-93.

12. Zur D, Iglicki M, Busch $\mathrm{C}$, et al. OCT Biomarkers as Functional Outcome Predictors in Diabetic Macular Edema Treated with Dexamethasone Implant. Ophthalmology. 2018;125:267-275.

13. Sun JK, Lin MM, Lammer J, et al. Disorganization of the Retinal Inner Layers as a Predictor of Visual Acuity in Eyes With Center-Involved Diabetic Macular Edema. JAMA Ophthalmol. 2014;132:1309-1316.

14. Bonfiglio V, Reibaldi M, Pizzo A, et al. Dexamethasone for unresponsive diabetic macular oedema: optical coherence tomography biomarkers. Acta Ophthalmol (Copenh). 2019;97:e540-544.

15. Cavalleri M, Cicinelli MV, Parravano M, et al. Prognostic role of optical coherence tomography after switch to dexamethasone in diabetic macular edema. Acta Diabetol. 2020;57:163-171 
16. Schreur V, Altay L, van Asten F, et al. Hyperreflective foci on optical coherence tomography associate with treatment outcome for anti-VEGF in patients with diabetic macular edema. PLOS ONE. 2018;13:e0206482.

17. Hwang HS, Chae JB, Kim JY, Kim DY. Association Between Hyperreflective Dots on Spectral-Domain Optical Coherence Tomography in Macular Edema and Response to Treatment. Invest Ophthalmol Vis Sci. 2017;58:5958-5967.

18. De Benedetto U, Sacconi R, Pierro L, et al. Optical coherence tomographic hyperreflective foci in early stages of diabetic retinopathy. Retina. 2015;35:449_ 453.

19. Zeng HY, Green WR, Tso MO. Microglial activation in human diabetic retinopathy. Arch Ophthalmol. 2008;126:227-232

20. Altmann C, Schmidt MHH. The Role of Microglia in Diabetic Retinopathy: Inflammation, Microvasculature Defects and Neurodegeneration. Int J Mol Sci. 2018;19:110

21. Framme C, Wolf S, Wolf-Schnurrbusch U. Small dense particles in the retina observable by spectral-domain optical coherence tomography in age-related macular degeneration. Invest Ophthalmol Vis Sci. 2010;51:5965-5969

22. Yoshitake T, Murakami T, Suzuma K, et al. Predictor of Early Remission of Diabetic Macular Edema under As-Needed Intravitreal Ranibizumab. Sci Rep. 2019;9:7599

23. Maggio E, Sartore M, Attanasio M, et al. Anti-Vascular Endothelial Growth Factor Treatment for Diabetic Macular Edema in a Real-World Clinical Setting. Am J Ophthalmol. 2018;195:209-22. 
24. Yoshitake T, Murakami T, Suzuma K, et al. Hyperreflective Foci in the Outer Retinal Layers as a Predictor of the Functional Efficacy of Ranibizumab for Diabetic Macular Edema. Sci Rep. 2020;10:873-873.

25. Park YG, Choi MY, Kwon JW. Factors associated with the duration of action of dexamethasone intravitreal implants in diabetic macular edema patients. Sci Rep. 2019;9:19588

26. Kim KT, Kim DY, Chae JB. Association between Hyperreflective Foci on Spectral-Domain Optical Coherence Tomography and Early Recurrence of Diabetic Macular Edema after Intravitreal Dexamethasone Implantation. J Ophthalmol. 2019;2019:3459164

27. Stroup DF, Berlin JA, Morton SC, Olkin I, Williamson GD, Rennie D, Moher D, Becker BJ, Sipe TA, Thacker SB. Meta-analysis of observational studies in epidemiology: a proposal for reporting. Meta-analysis Of Observational Studies in Epidemiology (MOOSE) group. JAMA. 2000 Apr 19;283:2008-12.

28. Study Quality Assessment Tools; National Heart, Lung, and Blood Institute (NHLBI) Available from: https://www.nhlbi.nih.gov/health-topics/study-qualityassessment-tools [accessed on 10th June 2020]

29. Suurmond R, van Rhee H, Hak T. Introduction, comparison, and validation of Meta $\square$ Essentials: A free and simple tool for meta $\square$ analysis. Res Synth Methods. 2017;8:537-553.

30. Framme C, Schweizer P, Imesch M, Wolf S, Wolf-Schnurrbusch U. Behavior of SD-OCT-detected hyperreflective foci in the retina of anti-VEGF-treated patients with diabetic macular edema. Invest Ophthalmol Vis Sci. 2012;53:5814-5818

31. Kang JW, Lee H, Chung H, Kim HC. Correlation between optical coherence tomographic hyperreflective foci and visual outcomes after intravitreal 
bevacizumab for macular edema in branch retinal vein occlusion. Graefes Arch Clin Exp Ophthalmol. 2014;252:1413-21.

32. Vujosevic S, Torresin T, Bini S, et al. Imaging retinal inflammatory biomarkers after intravitreal steroid and anti-VEGF treatment in diabetic macular oedema. Acta Ophthalmol (Copenh). 2017;95:464-471.

33. Fonollosa A, Zarranz-Ventura J, Valverde A, et al. Predictive capacity of baseline hyperreflective dots on the intravitreal dexamethasone implant (Ozurdex®) outcomes in diabetic macular edema: a multicenter study. Graefes Arch Clin Exp Ophthalmol. 2019;257:2381-2390.

34. Karttunen T, Nummelin L, Kaarniranta K, Kinnunen K. Real life experience of dexamethasone implant in refractory diabetic macular oedema. Clin Ophthalmol. 2019;13:2583-90.

35. Liu S, Wang D, Chen F, Zhang X. Hyperreflective foci in OCT image as a biomarker of poor prognosis in diabetic macular edema patients treating with Conbercept in China. BMC Ophthalmol. 2019;19:157.

36. Vujosevic S, Toma C, Villani E, et al. Diabetic macular edema with neuroretinal detachment: OCT and OCT-angiography biomarkers of treatment response to anti-VEGF and steroids. Acta Diabetol. 2020;57:287-296.

37. Narnaware SH, Bawankule PK, Raje D. Short-term outcomes of intravitreal dexamethasone in relation to biomarkers in diabetic macular edema. Eur $\mathbf{J}$ Ophthalmol. 2020;1120672120925788.

38. Chatziralli I, Theodossiadis P, Parikakis E, et al. Dexamethasone Intravitreal Implant in Diabetic Macular Edema: Real-Life Data from a Prospective Study and Predictive Factors for Visual Outcome. Diabetes Ther. 2017;8:1393-1404. 
39. Hatz K, Ebneter A, Tuerksever C, et al. Repeated Dexamethasone Intravitreal Implant for the Treatment of Diabetic Macular Oedema Unresponsive to AntiVEGF Therapy: Outcome and Predictive SD-OCT Features. Ophthalmol Int J Ophthalmol. 2018;239:205-214.

40. Vujosevic S, Berton M, Bini S, et al. Hyperreflective retinal spots and visual function after anti-vascular endothelial growth factor treatment in centerinvolving diabetic macular edema. Retina. 2016;36:1298-1308.

41. Menezo M, Roca M, Menezo V, Pascual I. Intravitreal dexamethasone implant Ozurdex in the treatment of diabetic macular edema in patients not previously treated with any intravitreal drug: a prospective 12-month follow-up study. Curr Med Res Opin. 2019;35:2111-2106.

42. Chatziralli IP, Sergentanis TN, Sivaprasad S. Hyperreflective foci as an independent visual outcome predictor in macular edema due to retinal vascular diseases treated with intravitreal dexamethasone or ranibizumab. Retina. 2016;36:2319-28.

43. Cusick M, Chew EY, Chan C-C, et al. Histopathology and regression of retinal hard exudates in diabetic retinopathy after reduction of elevated serum lipid levels. Ophthalmology. 2003;110:2126-2133.

44. Forstreuter F, Lucius R, Mentlein R. Vascular endothelial growth factor induces chemotaxis and proliferation of microglial cells. J Neuroimmunol. 2002;132:93-8. 45. Wong BS, Sharanjeet-Kaur S, Ngah NF, Sawri RR. The Correlation between Hemoglobin A1c (HbA1c) and Hyperreflective Dots (HRD) in Diabetic Patients. Int J Environ Res Public Health. 2020;17:3154 
medRxiv preprint doi: https://doi.org/10.1101/2021.04.16.21255622; this version posted April 18, 2021. The copyright holder for this preprint (which was not certified by peer review) is the author/funder, who has granted medRxiv a license to display the preprint in perpetuity. All rights reserved. No reuse allowed without permission.

46. Bolz M, Schmidt-Erfurth U, Deak G, et al. Optical Coherence Tomographic Hyperreflective Foci: A Morphologic Sign of Lipid Extravasation in Diabetic Macular Edema. Ophthalmology. 2009;116:914-20. 


\section{Figure Legends}

Figure 1: Flow diagram to summarize inclusion of relevant studies

Figure 2: A) Forest plot showing the change in quantitative HRS following intravitreal injection. There were a total of 12 studies among which there were 20 effect sizes to be analyzed. The box and whisker plot for individual studies represent the effect size (Hedges' g) and $95 \%$ confidence intervals $\left(\mathrm{CI}_{95 \%}\right)$. Subgroup analysis for dexamethasone and anti-VEGF groups are summarized within the plot. The overall effect size is represented by the polygon. B) Forest plot showing the association between HRS at baseline and change in VA. [* $\mathrm{G}=$ Hedges' $\mathrm{g}$; LCL=lower confidence limit; UCL=upper confidence limit; WGHT=weight of the study; dotted vertical line $=$ overall effect size; $\mathrm{I}^{2}=$ heterogeneity of the studies; within parenthesis=therapeutic group; $\quad \mathrm{VEGF}=$ vascular endothelial growth factor; DEX=dexamethasone; DRT=diffuse retinal thickening; $C M E=$ cystoid macular edema; $\mathrm{SRD}=$ serous retinal detachment; $\mathrm{R}=$ responder; $\mathrm{NR}=$ non-responder; $\mathrm{ER}=$ early recurrence; $\mathrm{LR}=$ late recurrence] 
medRxiv preprint doi: https://doi.org/10.1101/2021.04.16.21255622; this version posted April 18, 2021. The copyright holder for this preprint (which was not certified by peer review) is the author/funder, who has granted medRxiv a license to display the preprint in perpetuity.

All rights reserved. No reuse allowed without permission.

\section{Appendix 1}

Complete search strategy for PubMed (searched on 4th July 2020) 


\begin{tabular}{|c|c|c|c|c|c|c|c|c|}
\hline Author (year) & Study design & Study population & *Eyes & $\begin{array}{c}\text { Mean } \\
\text { age } \\
\text { (years) }\end{array}$ & $\begin{array}{l}\text { *Follow up } \\
\text { (months) }\end{array}$ & $\begin{array}{c}\text { Macular area } \\
\text { analyzed } \\
(\mu \mathrm{m})\end{array}$ & Intervention & $\begin{array}{l}\text { Study } \\
\text { quality }\end{array}$ \\
\hline Framme et al $(2012)^{30}$ & $\begin{array}{c}\text { Retrospective } \\
\text { cohort }\end{array}$ & $\begin{array}{c}\text { DME (previously no anti- } \\
\text { VEGF) }\end{array}$ & 51 & 67 & 1 & 1000 & $\mathrm{IVR}=30, \mathrm{IVB}=21$ & Moderate \\
\hline Vujosevic et al (2016) & $\begin{array}{l}\text { Prospective } \\
\text { case control }\end{array}$ & Treatment naive DME & 40 & 63.0 & 6 & $500-1500$ & IVR & High \\
\hline Kang et al $(2016)^{31}$ & $\begin{array}{c}\text { Retrospective } \\
\text { cohort }\end{array}$ & Treatment naive DME & 97 & 60.11 & $6.71 \pm 3.7$ & 1500 & IVB & Moderate \\
\hline Vujosevic et al $(2017)^{32}$ & $\begin{array}{l}\text { Retrospective } \\
\text { cohort }\end{array}$ & Treatment naive DME & 49 & 66.0 & Unclear & 3000 & DEX (23)/ IVR (26) & Moderate \\
\hline Chatziralli et al (2017) ${ }^{38}$ & $\begin{array}{c}\text { Prospective } \\
\text { cohort }\end{array}$ & Refractory DME & 54 & 69.2 & 12 & 3000 & DEX & Moderate \\
\hline Hwang et al (2017) $)^{17}$ & $\begin{array}{c}\text { Retrospective } \\
\text { cohort }\end{array}$ & Treatment naive DME & 82 & 55.13 & $\begin{array}{l}3 \mathrm{~m} \text { post } \mathrm{IVB} / \\
1 \mathrm{~m} \text { post } \mathrm{DEX}\end{array}$ & 3000 & $\begin{array}{l}3 \text { IVB; if no response } \\
\text { add DEX }\end{array}$ & Moderate \\
\hline Zur et al (2018) & $\begin{array}{l}\text { Retrospective } \\
\text { cohort }\end{array}$ & $\begin{array}{c}\text { Treatment naive and refractory } \\
\text { DME }\end{array}$ & 299 & 64 & 4 & 3000 & DEX & High \\
\hline Schreur et al (2018) & $\begin{array}{l}\text { Retrospective } \\
\text { cohort }\end{array}$ & Treatment naive DME & 54 & 67 & 3 & 3000 & IVR & High \\
\hline Hatz et al $(2018)^{39}$ & Case series & Refractory DME & 40 & 68.3 & 2 & 1000 & DEX & Moderate \\
\hline Bonfiglio et al (2019) & Case series & Refractory DME & 44 & 69.7 & 6 & 3000 & DEX & High \\
\hline Fonollosa et al $(2019)^{33}$ & $\begin{array}{c}\text { Retrospective } \\
\text { cohort }\end{array}$ & $\begin{array}{c}\text { Naive or previously treated } \\
\text { DME patients }\end{array}$ & 64 & 67.5 & 6 & 3000 & DEX & High \\
\hline Karttunen et al (2019) & $\begin{array}{l}\text { Retrospective } \\
\text { cohort }\end{array}$ & Refractory DME & 24 & 65.6 & 2 & 3000 & DEX & Moderate \\
\hline Menezo et al ( 2019) & $\begin{array}{l}\text { Prospective } \\
\text { cohort }\end{array}$ & Treatment naive DME & 50 & 66.4 & 12 & 3000 & DEX & Moderate \\
\hline Shulin Liu et al (2019) ${ }^{35}$ & $\begin{array}{l}\text { Retrospective } \\
\text { cohort }\end{array}$ & $\begin{array}{l}\text { DME (previously no anti- } \\
\text { VEGF) }\end{array}$ & 26 & 53.9 & 3 & 1000 & Conbercept & High \\
\hline Kim et al (2019) & $\begin{array}{l}\text { Retrospective } \\
\text { cohort }\end{array}$ & Refractory DME & 29 & 58.3 & 12 & 3000 & DEX & Moderate \\
\hline
\end{tabular}




\begin{tabular}{|c|c|c|c|c|c|c|c|c|}
\hline Vujosevic et al (2020) & $\begin{array}{l}\text { Retrospective } \\
\text { cohort }\end{array}$ & Treatment naive DME & 33 & 63.3 & $\begin{array}{l}3 \mathrm{~m} \text { post } \mathrm{IVR} / \\
2 \mathrm{~m} \text { post } \mathrm{DEX}\end{array}$ & 3000 & $\begin{array}{c}\text { DEX (15 eyes)/ IVR } \\
\text { (18) }\end{array}$ & Moderate \\
\hline Cavelleri et al $(2020)^{15}$ & $\begin{array}{l}\text { Retrospective } \\
\text { cohort }\end{array}$ & Treatment naive DME & 28 & 72.1 & 12 & 3000 & $\begin{array}{l}\text { Loading dose of IVR } \\
\text { followed by DEX }\end{array}$ & Moderate \\
\hline Yoshitake et al $(2020)^{24}$ & $\begin{array}{l}\text { Retrospective } \\
\text { cohort }\end{array}$ & DME (un-specified) & 77 & 69 & 12 & 1000 & IVR & High \\
\hline Narnaware et al $(2020)^{37}$ & $\begin{array}{l}\text { Prospective } \\
\text { cohort }\end{array}$ & $\begin{array}{c}\text { Treatment naive and refractory } \\
\text { DME }\end{array}$ & 27 & 61.11 & 4 & 1500 & DEX & Low \\
\hline
\end{tabular}




\begin{tabular}{|c|c|c|c|c|c|c|}
\hline \multicolumn{7}{|c|}{ Table 2: Quantitative HRS Change Following Intravitreal Therapy } \\
\hline \multirow[t]{2}{*}{ Author (year) } & \multirow{2}{*}{$\begin{array}{c}\text { Drug (Number of } \\
\text { eyes) }\end{array}$} & \multicolumn{5}{|c|}{ HRS $($ Mean \pm SD) } \\
\hline & & & & Baseline & After treatment & P value \\
\hline Framme et al $(2012)^{24}$ & IVR (30); IVB (21) & & & $16.02 \pm 8.0$ & $14.32 \pm 8.46$ & $0.000^{*}$ \\
\hline \multirow{3}{*}{ Vujosevic et al $(2016)^{35}$} & \multirow[t]{3}{*}{ IVR } & & ILM-IPL & $20.9 \pm 6.1$ & $18.4 \pm 8.7$ & 0.2993 \\
\hline & & & INL-OPL & $16.2 \pm 5.8$ & $13.8 \pm 5.8$ & 0.1986 \\
\hline & & & ONL & $4.8 \pm 2.8$ & $2.5 \pm 3.2$ & $0.02 *$ \\
\hline \multirow[t]{10}{*}{ Kang et al $(2016)^{25}$} & \multirow[t]{10}{*}{ IVB } & \multirow{3}{*}{ DRT } & TR & $16.97 \pm 5.68$ & $12.23 \pm 4.93$ & $<0.001 *$ \\
\hline & & & IR & $12.33 \pm 4.34$ & $8.97 \pm 3.77$ & $<0.001 *$ \\
\hline & & & OR & $4.63 \pm 2.94$ & $3.27 \pm 3.03$ & $0.01 *$ \\
\hline & & \multirow[t]{3}{*}{ CME } & TR & $14.62 \pm 4.45$ & $11.15 \pm 5.47$ & $0.002 *$ \\
\hline & & & IR & $10.21 \pm 4.69$ & $7.56 \pm 3.81$ & $0.004 *$ \\
\hline & & & OR & $4.56 \pm 2.08$ & $3.71 \pm 2.78$ & $0.047 *$ \\
\hline & & \multirow[t]{4}{*}{ SRD } & TR & $20.97 \pm 5.93$ & $12.82 \pm 5.23$ & $<0.001 *$ \\
\hline & & & IR & $11.76 \pm 3.66$ & $8.93 \pm 3.09$ & $0.002 *$ \\
\hline & & & OR & $7.33 \pm 2.78$ & $3.15 \pm 2.83$ & $<0.001 *$ \\
\hline & & & SRF & $1.88 \pm 2.04$ & $0.73 \pm 1.70$ & $0.003^{*}$ \\
\hline \multirow[t]{2}{*}{ Vujosevic et al $(2017)^{26}$} & \multirow[t]{2}{*}{ DEX (23); IVR(26) } & & DEX & $101.3 \pm 16.4$ & $68.8 \pm 10.4$ & $0.0001^{*}$ \\
\hline & & & IVR & $80.6 \pm 18.2$ & $52.5 \pm 14.1$ & $0.0001^{*}$ \\
\hline \multirow[t]{12}{*}{ Hwang et al $(2017)^{23}$} & \multirow{12}{*}{$\begin{array}{l}3 \text { IVB; if no response } \\
\text { add DEX }\end{array}$} & \multirow{3}{*}{ IVB Responder } & TR & $11.26 \pm 3.64$ & $8.72 \pm 3.44$ & $<0.001 *$ \\
\hline & & & IR & $7.46 \pm 2.74$ & $6.22 \pm 2.56$ & $0.002 *$ \\
\hline & & & OR & $3.59 \pm 1.67$ & $2.50 \pm 1.52$ & $<0.001 *$ \\
\hline & & \multirow{3}{*}{ IVB non-responder } & TR & $16.06 \pm 6.60$ & $17.00 \pm 5.39$ & 0.377 \\
\hline & & & IR & $11.50 \pm 4.95$ & $12.36 \pm 4.18$ & 0.262 \\
\hline & & & OR & $4.42 \pm 2.13$ & $4.58 \pm 1.96$ & 0.678 \\
\hline & & \multirow{3}{*}{ DEX responder } & TR & $20.78 \pm 3.34$ & $14.78 \pm 3.92$ & $<0.001 *$ \\
\hline & & & IR & $15.33 \pm 2.47$ & $10.72 \pm 3.34$ & $<0.001 *$ \\
\hline & & & OR & $5.38 \pm 1.97$ & $4.06 \pm 1.92$ & $<0.001 *$ \\
\hline & & \multirow[t]{3}{*}{ DEX non-responder } & TR & $14.00 \pm 3.85$ & $13.00 \pm 4.38$ & 0.53 \\
\hline & & & IR & $10 \pm 3.52$ & $8.67 \pm 4.18$ & 0.41 \\
\hline & & & OR & $4 \pm 1.55$ & $4.17 \pm 2.14$ & 0.74 \\
\hline \multirow[t]{3}{*}{ Schreur et al $(2018)^{22}$} & \multirow[t]{3}{*}{ IVR } & & TR & $14.8 \pm 9.7$ & $10.7 \pm 6.5$ & $0.002 *$ \\
\hline & & & IR & $10.4 \pm 7.3$ & $7.9 \pm 5.0$ & $0.01 *$ \\
\hline & & & OR & $4.5 \pm 4.9$ & $4.5 \pm 4.9$ & $0.013^{*}$ \\
\hline
\end{tabular}




\begin{tabular}{|c|c|c|c|c|c|c|}
\hline Hatz et al $(2018)^{34}$ & DEX & & & $10.9 \pm 7.9$ & $9.1 \pm 7.6$ & 0.077 \\
\hline \multirow[t]{6}{*}{ Kim et al (2019) } & \multirow[t]{6}{*}{ DEX } & \multirow{3}{*}{ Early recurrence group } & TR & $11.38 \pm 3.07$ & $7.19 \pm 2.29$ & NA \\
\hline & & & IR & $5.44 \pm 1.50$ & $3.69 \pm 1.14$ & $<0.001^{*}$ \\
\hline & & & OR & $5.94 \pm 2.74$ & $3.31 \pm 2.15$ & $<0.001^{*}$ \\
\hline & & \multirow[t]{3}{*}{ Late recurrence group } & TR & $7.54 \pm 3.60$ & $4.69 \pm 3.30$ & NA \\
\hline & & & IR & $4.08 \pm 1.70$ & $3.15 \pm 1.57$ & $0.027^{*}$ \\
\hline & & & OR & $3.46 \pm 2.30$ & $1.31 \pm 1.44$ & $0.001 *$ \\
\hline Karttunen et al (2019) ${ }^{28}$ & DEX & & & $67 \pm 20$ & $59 \pm 22$ & $0.04 *$ \\
\hline \multirow[t]{3}{*}{ Shulin Liu et al (2019) ${ }^{29}$} & \multirow{3}{*}{ Conbercept } & & IR & $5.39 \pm 4.24$ & $2.19 \pm 2.00(2 \mathrm{~m})$ & $0.002 *$ \\
\hline & & & OR & $5.15 \pm 5.17$ & $3.35 \pm 4.40(1 \mathrm{~m})$ & $<0.0001^{*}$ \\
\hline & & & SRF & $0.88 \pm 1.9$ & $0.08 \pm 0.27(1 \mathrm{~m})$ & $0.004 *$ \\
\hline \multirow[t]{2}{*}{ Vujosevic et al $(2020)^{30} \dagger$} & \multirow[t]{2}{*}{ DEX (15); IVR (18) } & & DEX & $85.5 \pm 16.9$ & $64.4 \pm 11.5$ & $0.0004 *$ \\
\hline & & & IVR & $72.7 \pm 15.7$ & $66.9 \pm 21.4$ & 0.36 \\
\hline Narnaware et al $(2020)^{31}$ & DEX & & & $23.88 \pm 10.31$ & $7.04 \pm 5.58$ & $<0.0001^{*}$ \\
\hline
\end{tabular}

IVR = Intravitreal ranibizumab; IVB= Intravitreal bevacizumab; DEX = Dexamethasone implant; IR= Inner retina; OR= Outer retina; TR= Total retina; SRF= Subretinal fluid;

ILM= Internal Limiting Membrane; INL= Inner Nuclear Layer; IPL= Inner Plexiform Layer; OPL= Outer Plexiform Layer; ONL= Outer Nuclear Layer; DRT= Diffuse Retinal

Thickening; $\mathrm{CME}=$ Cystoid macular edema; $\mathrm{SRD}=\mathrm{Sub}$ retinal detachment; ${ }^{*} \mathrm{p}<0.05, \mathrm{NA}=$ Not available; $†$ data obtained after contacting author 


\begin{tabular}{|c|c|c|c|c|c|c|}
\hline \multicolumn{7}{|c|}{ Table 3: Association between HRS and VA/ CMT } \\
\hline Author (Year) & \multicolumn{6}{|c|}{ Results } \\
\hline Framme et al (2012) 30 & \multicolumn{6}{|c|}{ No correlation between the HRS reduction and the course of VA / decrease in CMT } \\
\hline Vujosevic et al (2016) ${ }^{40}$ & \multicolumn{6}{|c|}{ Weak correlation between the number of HRS and BCVA ( $\mathrm{r}=-0.37)$ / CMT (Data not shown) } \\
\hline Kang et al $(2016)^{31}$ & \multicolumn{6}{|c|}{$\begin{array}{l}\text { Positive association between baseline number of HRS in OR and final VA (LogMAR) in DRT }\left(\beta_{\text {standardized }}=0.037 ; p=0.004\right) \text { and CME groups } \\
\left(\beta_{\text {standardized }}=0.048 ; p=0.002\right) \text { and between baseline number of HRS in IR and OR and final VA }\left(\text { LogMAR) in SRD group }\left(\beta_{\text {standardized }}=0.014,\right.\right. \\
0.024 \text { respectively; } p<0.04) \\
\text { The final foveal thickness showed no association with the baseline HRS counts }(p>0.2 \text { in all three groups })\end{array}$} \\
\hline Chatziralli et al $(2017)^{38}$ & \multicolumn{6}{|c|}{ Presence of HRS at baseline was associated with poorer visual outcomes (coefficient $=-6.02 ; \mathrm{CI}_{95 \%}=-10.12$ to $\left.-2.21 ; \mathrm{p}<0.001\right)$} \\
\hline Zur et al $(2018)^{12}$ & \multicolumn{6}{|c|}{$\begin{array}{l}\text { Absence of HRS at baseline predicted increased odds to gain }>10 \text { letters after } 4 \text { months }\left(\mathrm{OR}=5.33 ; \mathrm{CI}_{95 \%}=1.81-15.72 ; \mathrm{p}=0.002\right) \text { and good clinical } \\
\left.\text { response at } 4 \text { months (absent vs. present HRS: } \mathrm{OR}=3.66 ; \mathrm{CI}_{95 \%}=1.40-9.62 ; \mathrm{p}=0.01\right)\end{array}$} \\
\hline Schreur et al (2018) & \multicolumn{6}{|c|}{$\begin{array}{l}\text { No effect of baseline number of HRS on change in VA }(3 \mathrm{~m})\left(\beta_{\text {standardized }}=-0.002 ; \mathrm{CI}_{95 \%}=-0.009-0.004 ; \mathrm{p}=0.473\right) \\
\text { The number of HRS at baseline was independently associated with a decrease in } \mathrm{CMT}(3 \mathrm{~m})(\mathrm{p}=0.006) \text {. } \\
\text { Adequate responders had higher numbers of HRS at baseline than insufficient responders }\left(21.6 \pm 9.5 \text { versus } 12.7 \pm 8.8 ; \mathrm{OR}=1.106 ; \mathrm{CI}_{95 \%}=1.012-\right. \\
1.210 ; \mathrm{p}=0.030)\end{array}$} \\
\hline \multirow[t]{2}{*}{ Hatz et al $(2018)^{39}$} & & \multicolumn{2}{|c|}{ HRS $<15$} & \multicolumn{2}{|c|}{ HRS > 15} & $\mathbf{P}$ \\
\hline & Change in VA & \multicolumn{2}{|c|}{$8.0 \pm 7.7$} & \multicolumn{2}{|c|}{$3.1 \pm 12.0$} & 0.163 \\
\hline \multirow[t]{3}{*}{ Fonollosa et al (2019) ${ }^{33}$} & & \multicolumn{2}{|c|}{ HRS $<10$} & \multicolumn{2}{|c|}{ HRS $>21$} & \\
\hline & Change in VA & \multicolumn{2}{|c|}{$4.1(0.3$ to 7.9$)$} & \multicolumn{2}{|c|}{$4.4(1.3$ to 7.5$)$} & 0.336 \\
\hline & Change in CMT & -106.3 & o 152.7) & & & NA \\
\hline \multirow[t]{4}{*}{ Cavelleri et al $(2020)^{15}$} & & \multicolumn{2}{|c|}{ HRS $<13$} & \multicolumn{2}{|c|}{ HRS $>13$} & \\
\hline & \multirow[t]{2}{*}{ IVR (VA) } & Baseline & Final & Baseline & Final & \\
\hline & & $63.3 \pm 24.2$ & $76.3 \pm 17.1$ & $63.9 \pm 16.7$ & $63.1 \pm 21.3$ & NA \\
\hline & DEX (VA) & $79 \pm 15.4$ & $84.1 \pm 15$ & $59.6 \pm 22.2$ & $70.1 \pm 15.6$ & NA \\
\hline \multirow[t]{3}{*}{ Bonfiglio et al (2019) $^{14}$} & & \multicolumn{2}{|c|}{ HRS present at baseline } & \multicolumn{2}{|c|}{ HRS absent at baseline } & \\
\hline & VA & $52.3 \pm 6.4$ & $55.2 \pm 8.4$ & $51.4 \pm 8.9$ & $51.8 \pm 8.0$ & NA \\
\hline & CMT & $607 \pm 69$ & $493 \pm 123$ & $569 \pm 94$ & $510 \pm 125$ & NA \\
\hline \multirow[t]{3}{*}{ Menezo et al (2019) } & & \multicolumn{2}{|c|}{ HRS present at baseline } & \multicolumn{2}{|c|}{ HRS absent at baseline } & \\
\hline & Change in VA & \multicolumn{2}{|c|}{$7.6 \pm 11.3$} & \multicolumn{2}{|c|}{$8.6 \pm 15.9$} & 0.85 \\
\hline & Change in CMT & \multicolumn{2}{|c|}{$-130.4(142.6)$} & \multicolumn{2}{|c|}{$-102.5(143.9)$} & 0.49 \\
\hline Yoshitake et al $(2020)^{24}$ & & HRS pr & t baseline & & line & \\
\hline & Change in VA (LogMAR) $(6 \mathrm{~m})$ & & 138 & & & $0.022 *$ \\
\hline & Change in VA (LogMAR) (12m) & & 150 & & & $<0.001^{*}$ \\
\hline & Change in CMT & & & & & $0.028^{*}$ \\
\hline
\end{tabular}




\begin{tabular}{|c|c|}
\hline Shulin Liu et al (2019) ${ }^{35}$ & $\begin{array}{l}\text { Positive correlation between baseline number of HRS in OR and baseline VA }(r=0.42 ; p=0.034) \\
\text { Positive correlation between baseline number of HRS in the IR, OR and SRD and final VA }(r=0.571, p=0.002 ; r=0.464, p=0.017 ; \mathrm{r}=0.405, p=0.04 \\
\text { respectively). } \\
\text { No correlation between HRS reduction in OR and TR and increase in VA ( } \mathrm{r}=0.40, \mathrm{p}=0.043 \text { and } \mathrm{r}=0.393, \mathrm{p}=0.04 \text { respectively) } \\
\text { Positive correlation between HRS reduction in IR and TR and decrease in CMT ( } \mathrm{r}=0.422, \mathrm{p}=0.032 \text { and } \mathrm{r}=0.429, \mathrm{p}=0.029 \text { respectively). }\end{array}$ \\
\hline Narnaware et al $(2020)^{37}$ & Positive but not significant correlation between change in HRS and change in VA (LogMAR) $(r=0.3343 ; p>0.05)$ \\
\hline Vujosevic et al $(2017)^{32}$ & Inverse correlation between HRS number at baseline and CMT change $(q=-0.28, p=N A)$ \\
\hline
\end{tabular}


medRxiv preprint doi: https://doi.org/10.1101/2021.04.16.21255622; this version posted April 18, 2021. The copyright holder for this preprint (which was not certified by peer review) is the author/funder, who has granted medRxiv a license to display the preprint in perpetuity.

All rights reserved. No reuse allowed without permission.

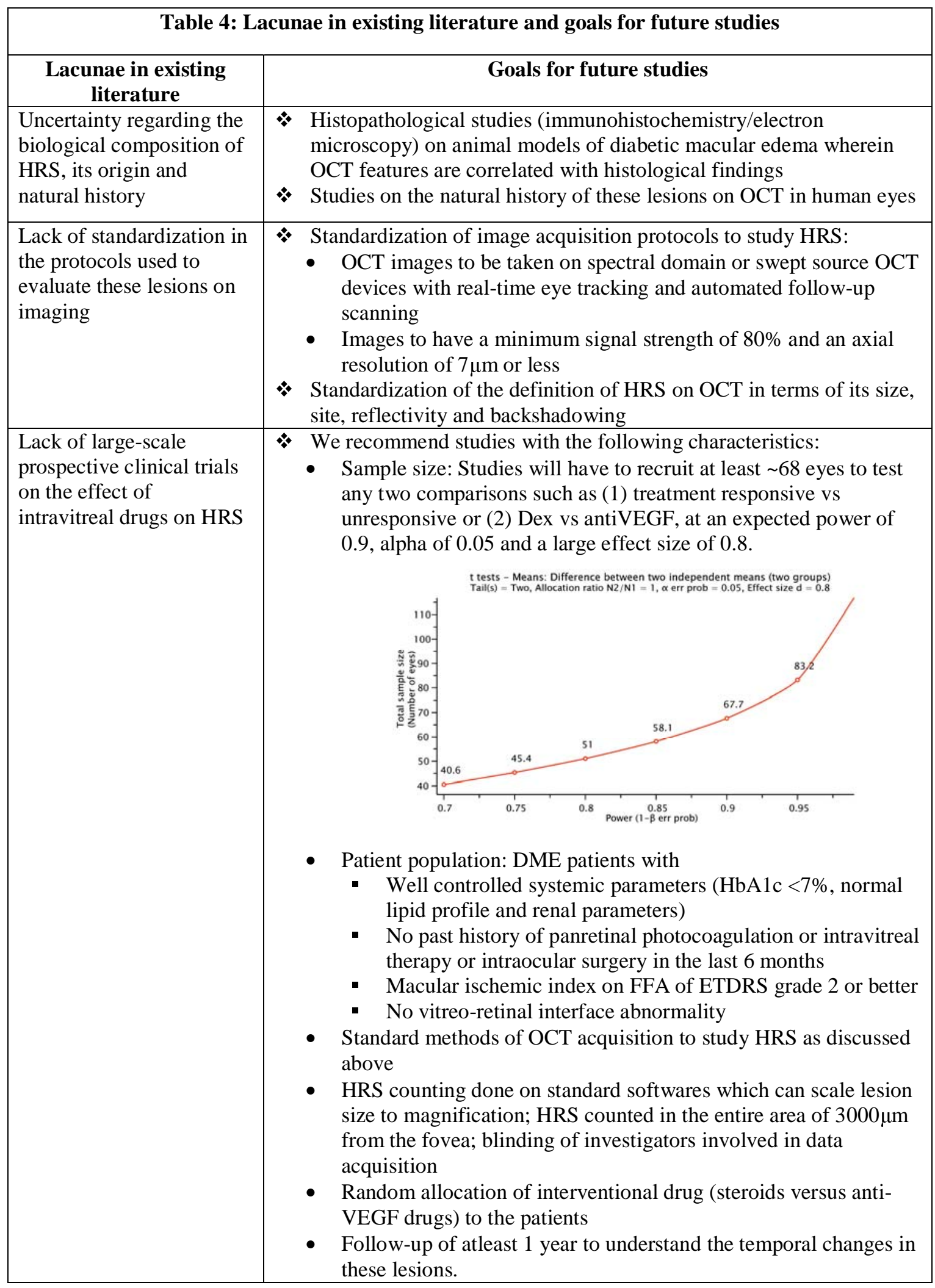


Records identified through database searching $(n=12969)$

Scopus: 6063; Pubmed: 524; Proquest:

2169; Web of science: 3519 ;

CINAHL: 204; Wiley online: 490
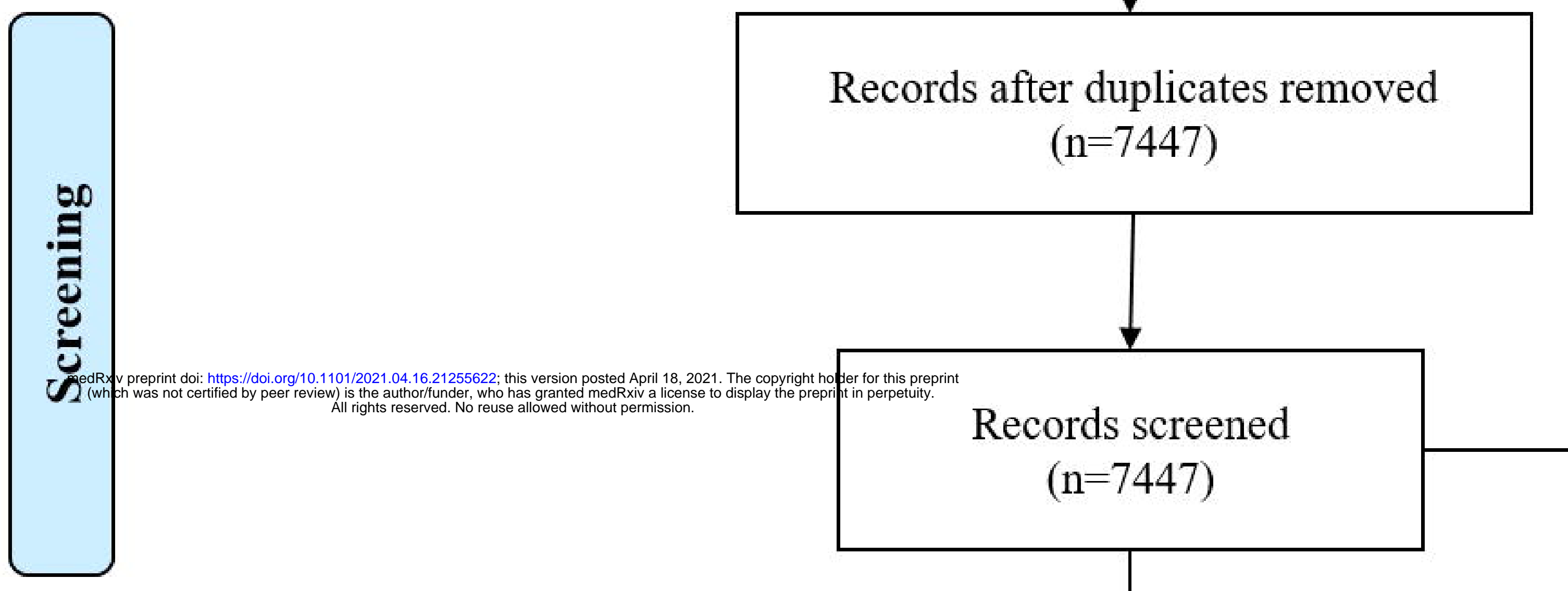

Records after duplicates removed $(\mathrm{n}=7447)$
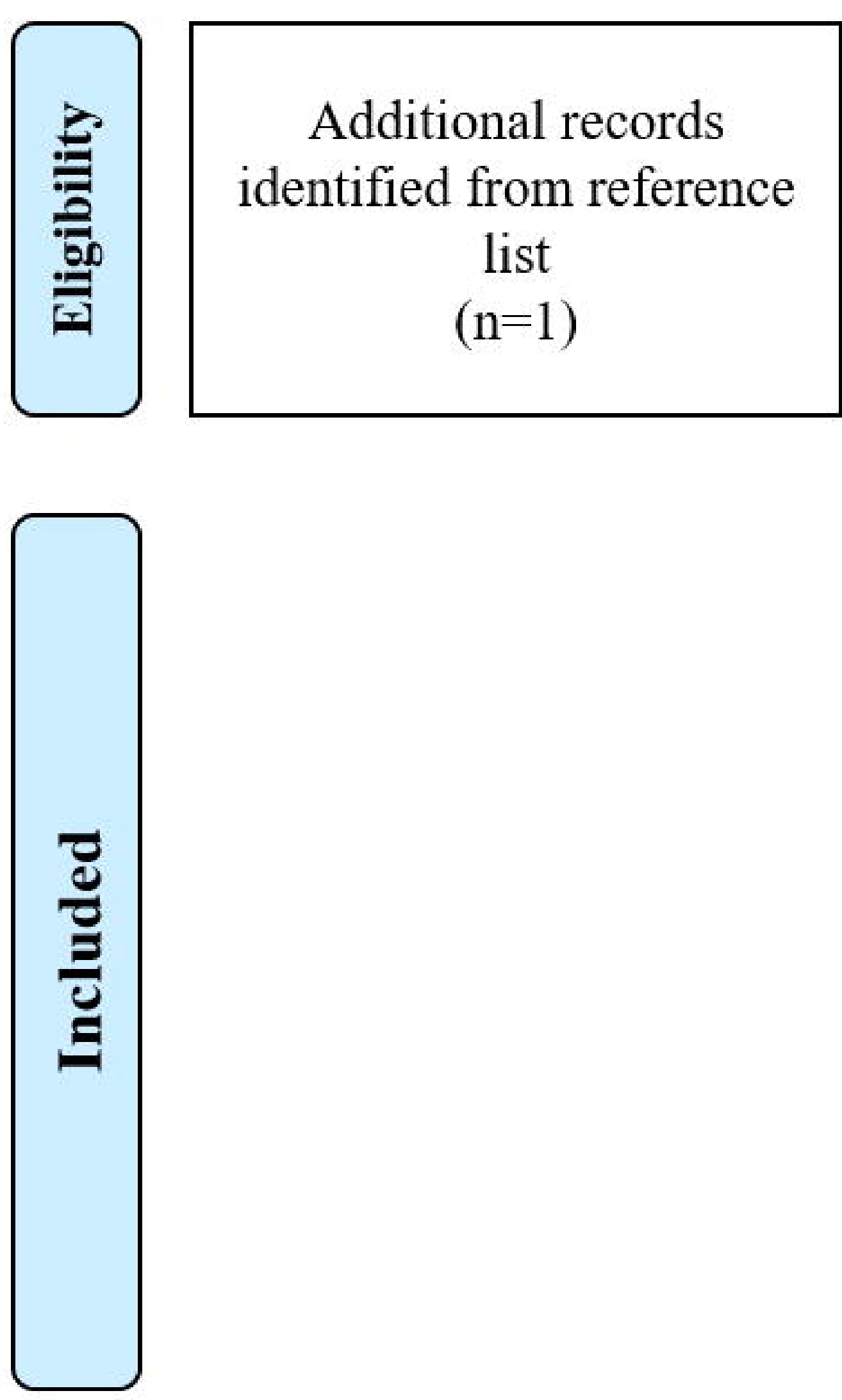

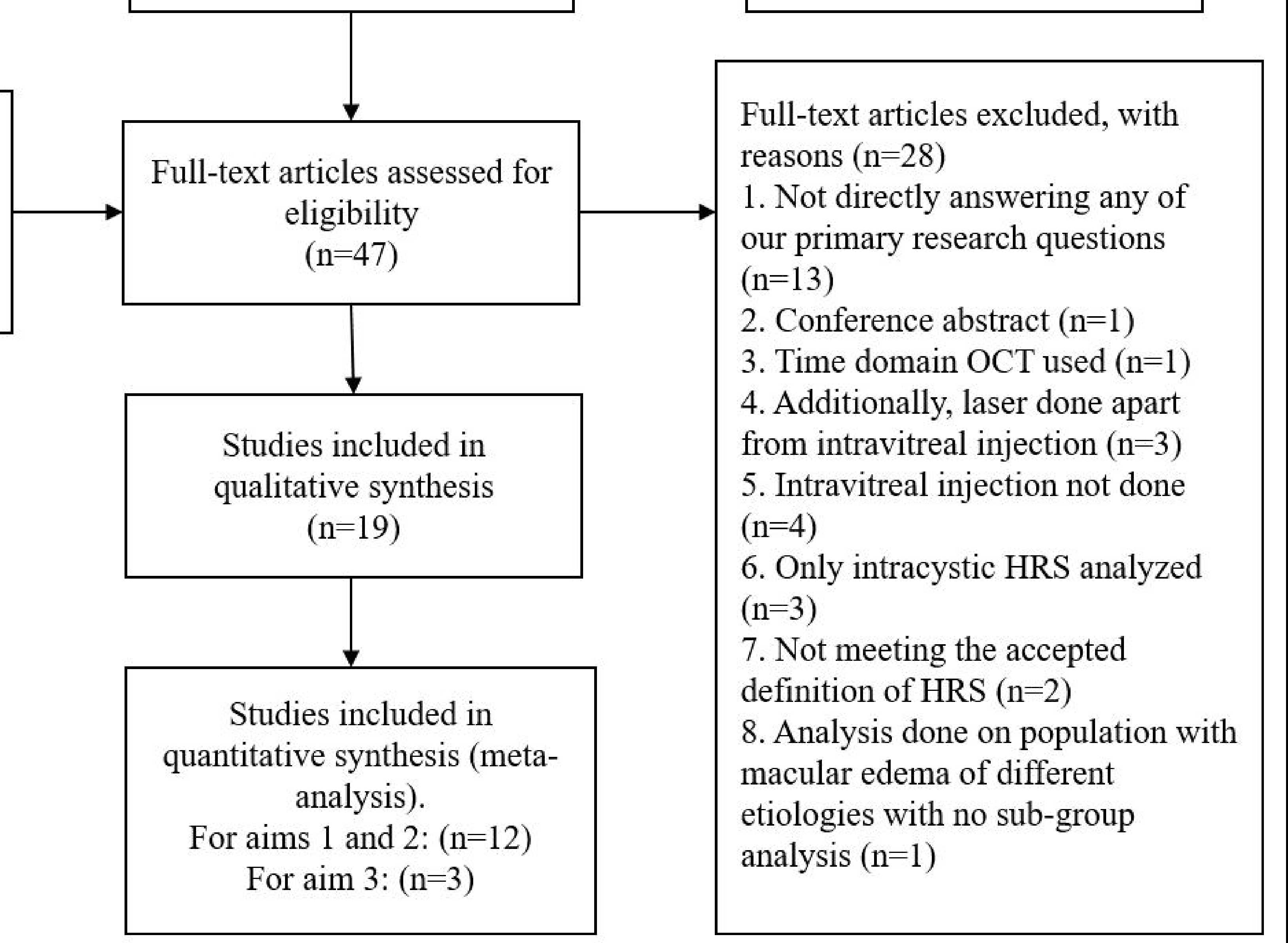


